\title{
An Investigation on Organic Matter Removal from Wastewater by Local Groundnut Shell Derived Adsorbent from Salgar Budruk-Kinetic, Isotherm and Parameter Studies
}

\author{
Dr. Sunil J. Kulkarni \\ Chemical Engineering Department, Datta Meghe College of Engineering, Airoli, Navi Mumbai, \\ 400708, Maharashtra, India
}

*Corresponding Author: Dr. Sunil J. Kulkarni, Chemical Engineering Department, Datta Meghe College of Engineering, Airoli, Navi Mumbai, 400708, Maharashtra, India

\begin{abstract}
Removal of organic matter is normally done by activated sludge process in conventional plants. Studies have revealed that these plants are not effective and there is need for advanced treatment method for tackling the problem. The present work includes review of some investigations on various advanced methods for COD removal. Also experimental resluts of batch and column experiments for COD removal by using groundnut shell adsorbent are reported in the present paper.The parameters affecting the adsorption were studied and optimum values of these parameters were estimated. For the initial 0.5 to 1.5 grams of adsorbent, comparatively steep drop in concentration is observed. The central part of the curve indicates almost linear drop in COD with increase in adsorbent dosage.At lower $\mathrm{pH}$, the $\mathrm{H}^{+}$ions compete with adsorbate for the sites. At higher $\mathrm{pH}$, there can be formation of complex ions or there can be hydroxides formation and subsequent precipitation also.
\end{abstract}

Keywords: Chemical oxygen demand, dissolved oxygen, concentration. isotherm, kinetics.

\section{INTRODUCTION}

The treatment was distillery wastewater is important asepct of sustainable growth of agro economy. The distilleries provides value addition to the sugar industry wastewater. The wastewater contains high amount of organic matter. This organic matter consumes dissolved oxygen(DO). The permissiblem minimum dissolve oxygen is $5 \mathrm{mg} / \mathrm{l}$ and desirable is $10 \mathrm{mg} / \mathrm{l}$. The water with low DO smells very bad and not suitable for use. Removal of organic matter is normally done by activated sludge process in conventional plants. Studies have revealed that these plants are not effective and there is need for advanced treatment method for tackling the problem. The present work includes review of some investigations on various advanced methods for COD removal. Also experimental resluts of batch and column experiments for COD removal by using groundnut shell adsorbent are reported in the present paper.

\section{LITERATURE REVIEW}

The chemical oxygen demand and biological oxygen demand are important indicators of the dissolved oxygen content of the wastewater. Various studies have been reported on removal of the organic matter and subsequent effect on dissolved oxygen[1-5]. Various investigations on effect of organic matter on river and resrviors indicate that the orgaic matter with high COD is reaching alarming level in the country. A review on modelling of packed beds for wastewater treatment was presented by Kulkarni [6].Accrding to him, various models like Thomas model, Yoon Nelson model and Modified Dose model are used for describing breakthrough curves. Amale et.al.used wood charcoal as an adsorbent in a fixed bed for removal of organic matter from effluent[8]. They observed decrease in exhaustion time with initial concentration. With increase in bed height, the exhaustion time delayed. Dairy wastewater treatment by anaerobic fixed bed reactors was carried out by Nikolaeva et.al.[8].They used hybrid material composed of waste tyre rubber and zeolite.They observed that increase in the hydraulic retention time(HRT) brought about an improvement in the effluent quality.Kulkarni and Goswami used bagasse flyash as an adsorbent for organic matter removal from wastewater[9]. They carried out investigation in batch and column modes with satisfactory results.Electrocoagulation was used for organic matter removal by Khandegar and Saroh[10].They 
obtained COD removal efficiency was $84.6 \%$ and $76.9 \%$ at initial $\mathrm{pH}$ (7.2). Many investigations have been varried out for COD removal by using various advanced biological treatment[11-14]. These treatment includes both, aerobic and anaerobic methods. Advanced methods including membrane separations such as pervaporation, reverse osmosis, electrodialysis are also used in few investigations[15-19]. These methods are costly but yield very high quality water.Also chemical treatments using various coagulants and flocculants have been used in various investigations[20-23].

\section{METHODOLOGY}

Batch experiments were carrid out with $150 \mathrm{ml}$ of the saple volume. The effluent from the distillery was treated by using groundnut shell adsorbent. The adsorbent was prepared by thermal and chemical activation. The analysis of the sample was done for COD and colour. COD was measuerd by usind usual method involving potassium dischromate and COD digestion apparatus( Spectralab SL 159). Absorbance was nalysed by using U.V. spectrophotometer(Elico). The column operation was carreid ou with 1:1 mix adsorbent. The fillter used was sand. The column was $5 \mathrm{~cm}$ in diameter and $15 \mathrm{~cm}$ in height. The volumetric flow rate was $20 \mathrm{ml} / \mathrm{min}$.

\section{RESULT AND DISCUSSION}

\subsection{Effect of Adsorbent Dose on COD and Percent Removal}

Effect of adsorbent dose on COD and percent removal is shown in fig.1 A,B. Initial experiments were carried out for contact time of 3 hours. There was almot linear decrease in the percentage removal for part of the curve. The curve becomes flat of dosage more than 4 grams per $150 \mathrm{ml}$. For the initial 0.5 to 1.5 grams of adsorbent, comparatively steep drop in concentration is observed. The central part of the curve indicates almost linear drop in COD with increase in adsorbent dosage. Overall curve, when approximated as a straightline was having $\mathrm{R}^{2}$ value above 0.9 , which can be considered satisfactory. For 4 gram of the adsorbent maximum 70 percent removal was obtained. The further increase in dosage doent have any significant effect on removal percentage. The reason can insufficient contact due to dense slurry formation. For initial concentration of $1205 \mathrm{mg} / \mathrm{l}$, final minimium concentration was $350 \mathrm{mg} / \mathrm{l}$. For higher initial concentration $(6050 \mathrm{mg} / \mathrm{l})$, maximum removal was 68 percent for 10 grams of adsorbent. The removal floowed better fit to a straightline(Fig.1B).

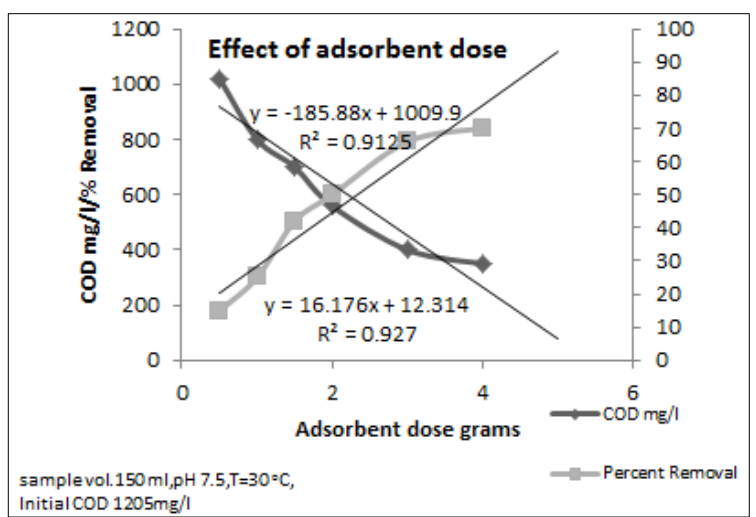
InitialCOD $1205 \mathrm{mg} / \mathrm{l}$

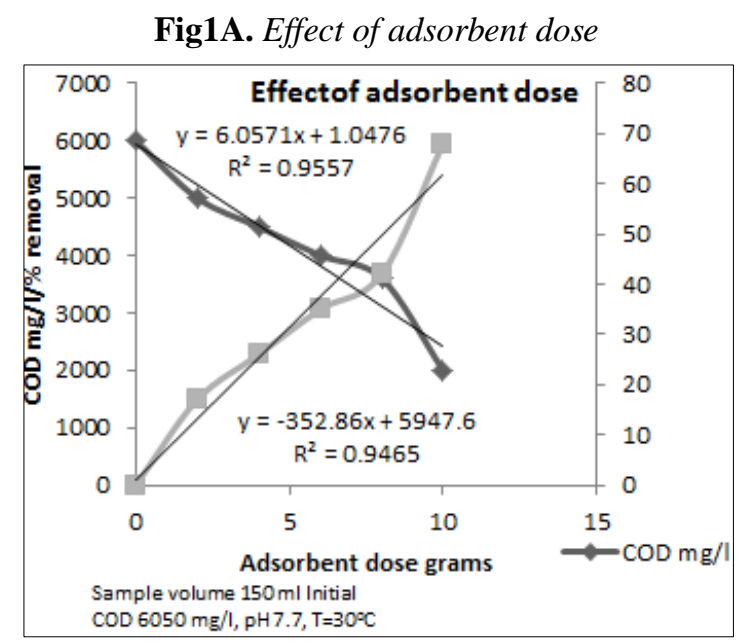

Fig1B. Effect of adsorbent dose 
An Investigation on Organic Matter Removal from Wastewater by Local Groundnut Shell Derived Adsorbent from Salgar Budruk-Kinetic, Isotherm and Parameter Studies

\subsection{Effect of $\mathbf{p H}$}

Fig. 2 depicts effect of $\mathrm{pH}$ on COD removal. The COD removal was highest for $\mathrm{pH}$ value between 5 to 6. At lower $\mathrm{pH}$, the $\mathrm{H}^{+}$ions compete with adsorbate for the sites. At higher $\mathrm{pH}$, there can be formation of complex ions or there can be hydroxides formation and subsequent precipitation also.

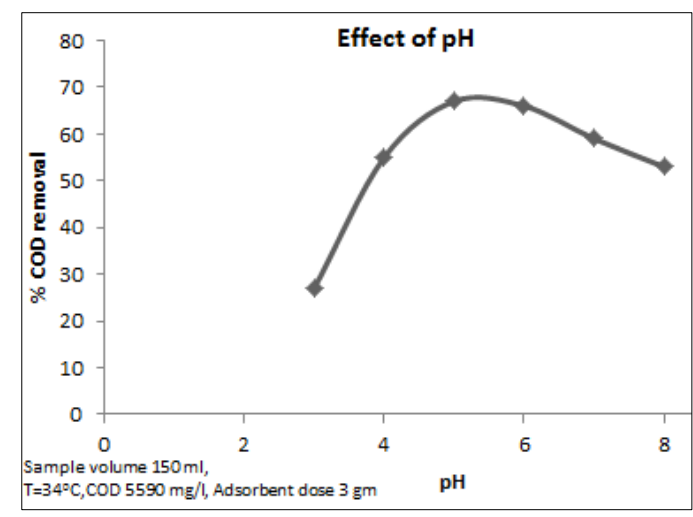

Fig2. Effect of $p H$

\subsection{Effect of Contact Time}

Effect of contact time on COD removal is shown in fig.3. The middle portion of the curve is linear. The linearized line for COD and removal curves has $\mathrm{R}^{2}$ values more than o.9. After 150 minutes of contact time, the percentage removal was stable at $64 \%$ with negligible rise for next time intervals. This is indication of equilibrium. So optimum contact time was 150 minutes.

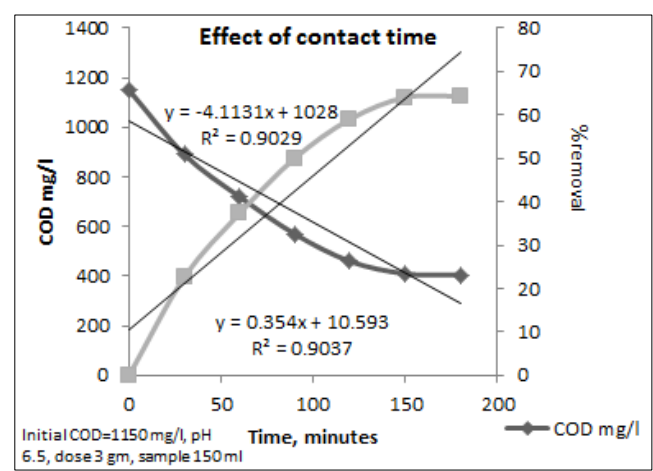

Fig3. Effect of contact time

\subsection{Effect of Initial Concentration}

Effect of initial concentration on COD removal and COD is shown in fig.4. For initial COD upto 2000 $\mathrm{mg} / \mathrm{l}$ there was steep rise in the COD followed by equation $=0.0223 \mathrm{x}+6.3$ with $\mathrm{R}^{2}=0.9852$. For further increase in initial COD the rise in removal becomes flat. There is no appreciable rise in removal or reduction in COD. The later part of the line follows the equationy $=0.0025 x+46.667$ with $\mathrm{R}^{2}=0.9868$. It can be seen that the slope decreased by 9 times for later part of the line. The reason can be exhaustion of adsorbent capacity and hindrance by the adsorbates for each other's movement, affecting the reach of adsorbate to the adsorbent.

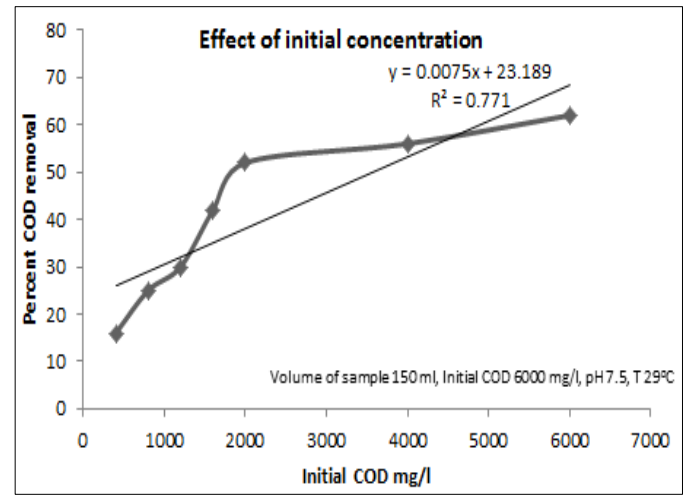

Fig4. Effect of initial concentration 
An Investigation on Organic Matter Removal from Wastewater by Local Groundnut Shell Derived Adsorbent from Salgar Budruk-Kinetic, Isotherm and Parameter Studies

\subsection{Freundlich Isotherm}

Freundlich equation is given by

$\mathrm{X} / \mathrm{M}=\mathrm{K} \mathrm{C}^{1 / \mathrm{n}}, \mathrm{C}$ is equilibrium concentration, $\mathrm{X}$, adsorbate adsorbed and $\mathrm{m}$, amount of adsorbent. The

The data was plotted to fit in Freundlich equation. Fig. 5 indicates Freundlich isotherm equation. The data followed the equation with $\mathrm{R}^{2}$ value $0.9009 .1 / \mathrm{n}$ value was found to be 0.0104 .

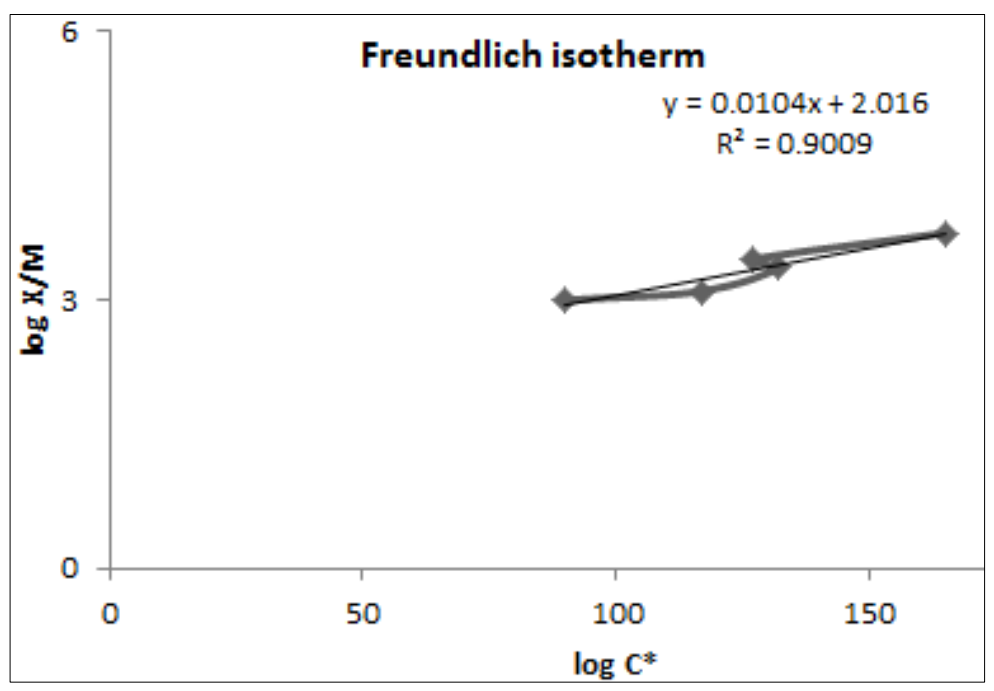

Fig5. Freundlich isotherm

\subsection{Continuous Operation}

The colour removal was significant for 120 minutes. The colour removal dropped thereafter. Initial 120 minutes of flat rise in the COD is followed by steep rise in COD. First 150 minutes of the column operation were found to follow the equation, $1.0804 x+187$ with $\mathrm{R}^{2}=0.906$. The later portion of the curve followed, $\mathrm{y}=19.6 \mathrm{x}-3456$ with $\mathrm{R}^{2}=0.9434$. It can be said that the curve can be divided into two linear portions flowing separate straight line equation. Fig. 6 depicts colour and COD variations for continuous column.Fig.7 shows absorption at various time intervals. It was seen that unlike COD, this plot doesn't show any particular trend. Initial decrease in absorptivity is followed by increase and again decrease. This indicates that COD and colour are not related linearly. There are other pollutants, which are imparting colour and having some interactions with the adsorbent.

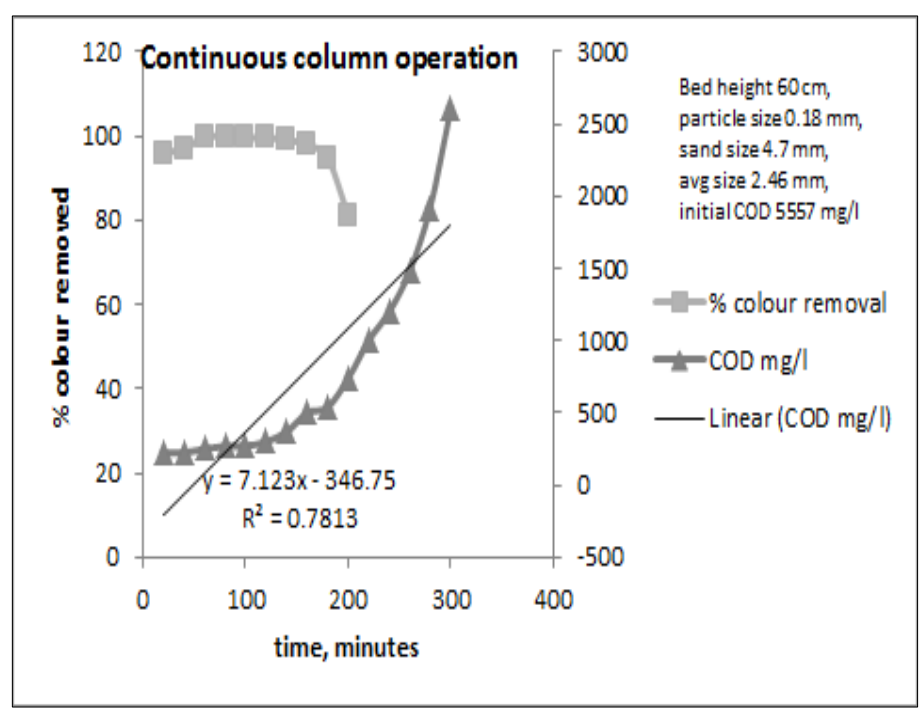

Fig6. Continuous column operation 


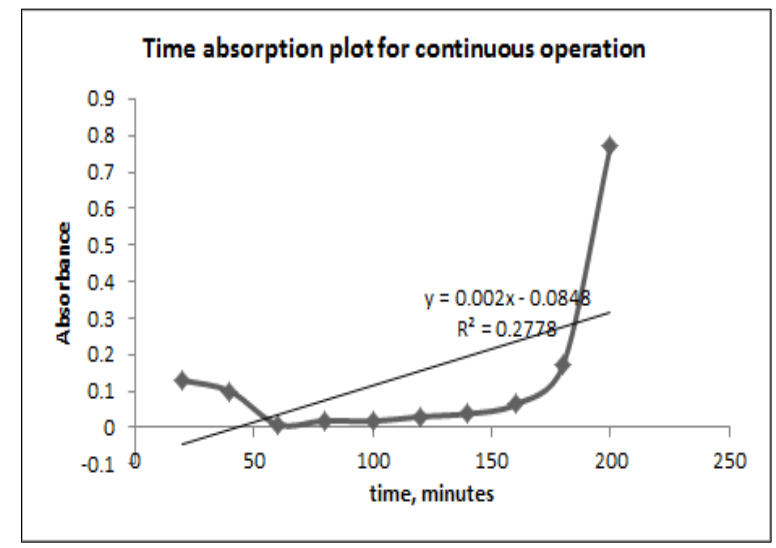

Fig7. Time-absorption plot for continuous operation

\subsection{Kinetics of COD Removal}

Removal curve can be expresses as

$$
\text { As }=K t^{m}
$$

Where $A_{s}=$ percent removal, $t$, time and $K$, the rate constant .

The plot of percentage removal verses time indicated satisfactory fit for first order kinetics with $\mathrm{R}^{2}$ value above 0.9 .

Here, $y=1.6806 x-0.7972$ with $R^{2}=0.9833$

The value of $\mathrm{m}$ was observed to be 1.68 .

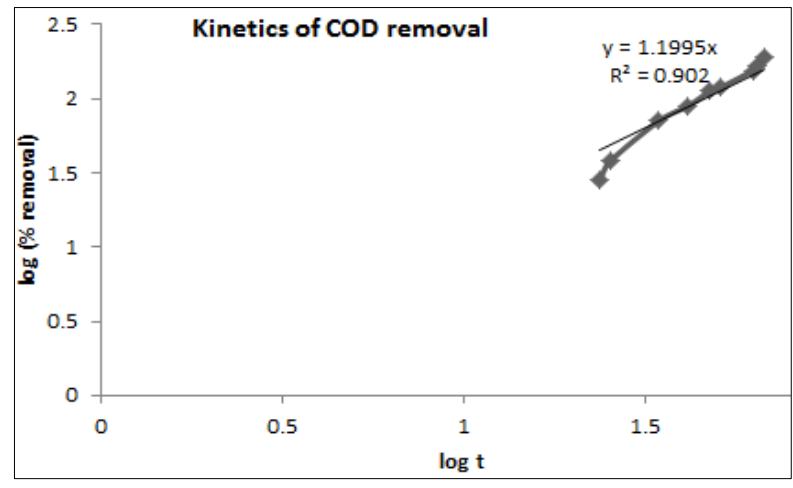

Fig8. Kinetics of COD removal

\section{CONCLUSION}

The parameters affecting the adsorption were studied and optimum values of these parameters were estimated. The present work includes review of some investigations on various advanced methods for COD removal. Also experimental resluts of batch and column experiments for COD removal by using groundnut shell adsorbent are reported in the present paper.The data followed the equation with $\mathrm{R}^{2}$ value 0.9009 . $1 / \mathrm{n}$ value was found to be 0.0104 . For the initial 0.5 to 1.5 grams of adsorbent, comparatively steep drop in concentration is observed. The central part of the curve indicates almost linear drop in COD with increase in adsorbent dosage. At lower $\mathrm{pH}$, the $\mathrm{H}^{+}$ions compete with adsorbate for the sites. At higher $\mathrm{pH}$, there can be formation of complex ions or there can be hydroxides formation and subsequent precipitation also.

\section{REFERENCES}

[1] D.K. Gautam, Effect of Pollution on Dissolved Oxygen Concentration in Stream of Shivalik Himalayas- a Case Study, Int. Journal on Life Science and Pharma, 2011,1(1), pp.77-80.

[2] Sunil J. Kulkarni, Suhas V Patil, and Y. P. Bhalerao,"Flyash Adsorption Studies for Organic Matter Removal Accompanying Increase in Dissolved Oxygen" International Journal of Chemical Engineerng Applications, Dec.2011, vol.2,no.6.,434-438. 
An Investigation on Organic Matter Removal from Wastewater by Local Groundnut Shell Derived Adsorbent from Salgar Budruk-Kinetic, Isotherm and Parameter Studies

[3] Sunil J. Kulkarni,Analysis of Dissolved Oxygen Deficit in a Flowing Stream,Int. J. of Thermal \& Environmental Engineering Volume 15, No. 2 (2017) 97-102.

[4] Kulkarni SJ. A review on research and studies on dissolved oxygen and its affecting parameters. Int J Res Rev. 2016; 3(8):18-22.

[5] C. A. Frieder, S. H. Nam, T. R. Martz, and L. A. Levin1, "High temporal and spatial variability of dissolved oxygen and pH in a Nearshore California Kelp Forest”, Biogeosciences, 2012, 9, 39173930.

[6] Sunil J. Kulkarni , -Modeling for Adsorption Columns for Wastewater Treatment: a Reviewl, International Journal of Innovative Research in Engineering \& Multidisciplinary Physical Sciences(IJIRMPS), Vol. 2,No. 2, pp.7-11,October 2014.

[7] Pallavi Amale, Sunil Kulkarni, Kavita Kulkarni, - Studies on Packed Bed Treatment for Organic Matter in Distillery Effluent -,International Journal of Engineering Science and Innovative Technology (IJESIT), Vol. 3, No. 5, pp.268-272, September 2014.

[8] Nikolaeva, S., Sánchez, E. and Borja, R., -Dairy Wastewater Treatment by Anaerobic Fixed bed Reactors from Laboratory to pilot-scale plant: A case study in Costa Rica Operating at Ambient Temperature -,Int. J. Environ. Res.,Vol. 7, No.3, pp.759-766,Summer 2013.

[9] Sunil J. Kulkarni, Ajaygiri K. Goswami,-Adsorption Studies for Organic Matter Removal from Wastewater by Using Bagasse Flyash in Batch and Column Operationsll, International Journal of Science and Research, Vol. 2, No. 11,pp.180-183,November 2013.

[10] V. Khandegar and Anil K. Saroh, "Treatment of Distillery Spentwash by Electrocoagulation", Journal of Clean Energy Technologies, Vol. 2, No. 3,pp.244-247,2014.

[11] K. Rani, V. Sridevi, R. Srinu Venkat Rao, K. Vijay Kumar \& N. Harsha, "Biological Treatment Of Distillery Waste Water - An Overview", International Journal of General Engineering and Technology, Vol. 2, No. 4, pp. 15-24,2013.

[12] Alexander Aivasidis , Vasileios I.Diamantis, "Biochemical Reaction Engineering and Process Development in Anaerobic Wastewater Treatment", Adv Biochem Engin/Biotechnol, Vol.92,pp.4976,2005 .

[13] R Kumaresan, N. Sundara Ramakrishnan and C. Premalatha, "Aerobic Treatment of Distillery Wastewater in a Three Phase Fluidized Bed Biofilm Reactor", International Journal of Chemical Engineering Research ,Vol.1, No. 1, pp. 13-20,2009.

[14] X.L. Melamane, P.J. Strong and J.E. Burgess, "Treatment of Wine Distillery Wastewater:A Review with Emphasis on Anaerobic Membrane Reactors”, S. Afr. J. Enol. Vitic., Vol. 28, No. 1, pp.2536,2007.

[15] Pawar Avinash Shivajirao, "Treatment Of Distillery Wastewater Using Membrane Technologies", International Journal of Advanced Engineering Research and Studies ,Vol.1, No.3,pp.275-283,2012.

[16] Rashmi Vinod Dahake, A.K.Goswami, Dr. V. Kalyanraman, S.J.Kulkarni, Performance Evaluation Of Hybrid Membrane Bioreactor For Low Strength Wastewater Treatment, International Journal Of Science, Engineering And Technology Research (IJSETR), 2013, 2(12), 2167-2169.

[17] Sunil J. Kulkarni, Ajaygiri K. Goswami, Applications And Advancements In Treatment Of Waste Water By Membrane Technology- A Review, International Journal Of Engineering Sciences \& Research Technology, 2014, 3(9), 446-449.

[18] Jain Jyoti, Dubey Alka and Singh Jitendra Kumar, Application of Membrane-Bio-Reactor in WasteWater Treatment: A Review, International Journal of Chemistry and Chemical Engineering, 2013, 3(2), 115-122.

[19] Kulkarni SJ. A review on studies and research on use of pervaporation as separation method. Int J Res Rev. 2016; 3(1):81-85.

[20] Sunil Jayant Kulkarni,An Insight into Electro-dialysis for Water Treatment,International Journal of Scientific Research in Science and Technology (www.ijsrst.com),March-April-2017 [(2)3: 506-509.

[21] C. Peng, S. Song, S. Lu, A. Lopez-Valdivieso (2004). Electroplating Wastewater Treatment through Chemical Precipitation and Electrodialysis. The European Journal of Mineral Processing and Environmental Protection, 4(3), pp. 210-215.

[22] Sunil Jayant Kulkarni,An Insight into Research and Investigations on Froth Flotation,International Journal of Scientific Research in Chemistry, 2016,Volume 1 | Issue 1,55-58.

[23] Achusim-Udenko, A. C. Onyedika Gerald, Ogwuegbu Martins and Ayuk Ausaji(2011). Flotation Recovery of Barite from Ore Using Palm Bunch Based Collector. Int. J. Chem. Sci., 9(3), pp.1518-1524. 


\section{AUTHOR'S BIOGRAPHY}

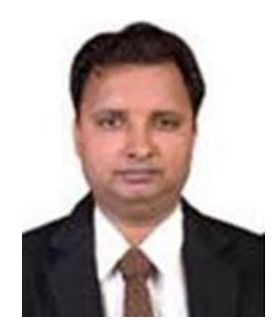

Sunil J. Kulkarni, has completed his $\mathrm{PhD}$ from Sant Gadge baba Amravati University and Masters in Chemical Engineering from Tatyasaheb Kore Institute of Engineering and Technology, Warananagar. He is working as Assistant Professor in Chemical Engineering Department of Datta Meghe College of Engineering, Airoli, Navi Mumbai, India. He has 15 years of teaching and research experience. Dr. Sunil is involved with different academic activities across the universities in Maharashtra. His area of investigation in doctoral studies is phenol and heavy metal removal from waste water. $\mathrm{He}$ has also worked on kinetics and isotherms of various sorption operations. He has published more than 200 international review and research papers and presented 15 research papers in international conferences. He has also published four books on heat recovery, wastewater treatment and biotechnology related subjects. His area of research includes adsorption, clean technology and environmental biotechnology. He is on the reviewer board of many international journals and reviewed many international papers. He is also governing body member, promotional editor and executive member of many reputed international journals.

Citation: S. Kulkarni, "An Investigation on Organic Matter Removal from Wastewater by Local Groundnut Shell Derived Adsorbent from Salgar Budruk-Kinetic, Isotherm and Parameter Studies", International Journal of Advanced Research in Chemical Science (IJARCS), vol. 4, no. 12, pp. 41-47, 2018. http://dx.doi.org/10.20 431/2349-0403.0412005

Copyright: (1) 2017 Authors. This is an open-access article distributed under the terms of the Creative Commons Attribution License, which permits unrestricted use, distribution, and reproduction in any medium, provided the original author and source are credited. 